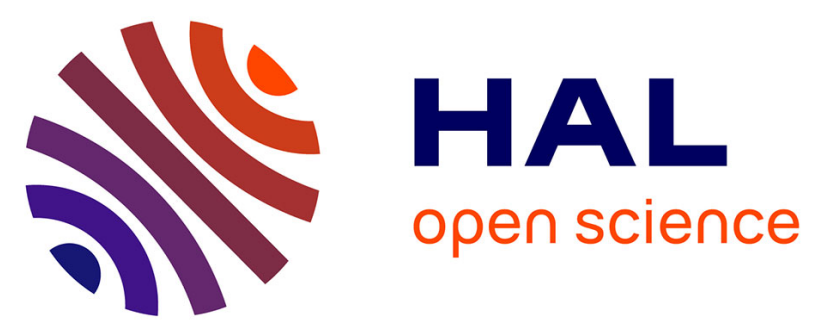

\title{
The anatomic relationship between the internal jugular vein and the carotid artery in children after laryngeal mask insertion. An ultrasonographic study.
}

Ravi Gopal Nagaraja, Morven Wilson, Graham Wilson, Bruno Marciniak, Thomas Engelhardt

\section{To cite this version:}

Ravi Gopal Nagaraja, Morven Wilson, Graham Wilson, Bruno Marciniak, Thomas Engelhardt. The anatomic relationship between the internal jugular vein and the carotid artery in children after laryngeal mask insertion. An ultrasonographic study.. Pediatric Anesthesia, 2010, 21 (1), pp.62. 10.1111/j.1460-9592.2010.03459.x . hal-00600133

\section{HAL Id: hal-00600133 https://hal.science/hal-00600133}

Submitted on 14 Jun 2011

HAL is a multi-disciplinary open access archive for the deposit and dissemination of scientific research documents, whether they are published or not. The documents may come from teaching and research institutions in France or abroad, or from public or private research centers.
L'archive ouverte pluridisciplinaire $\mathbf{H A L}$, est destinée au dépôt et à la diffusion de documents scientifiques de niveau recherche, publiés ou non, émanant des établissements d'enseignement et de recherche français ou étrangers, des laboratoires publics ou privés. 


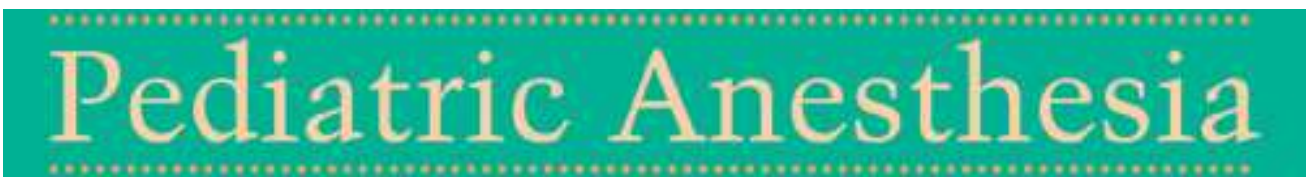

The anatomic relationship between the internal jugular vein and the carotid artery in children after laryngeal mask insertion. An ultrasonographic study.

\begin{tabular}{|r|l|}
\hline Journal: & Pediatric Anesthesia \\
\hline Manuscript ID: & PAN-2010-0392.R1 \\
\hline Manuscript Type: & Original Paper \\
\hline Author: & 12 -Oct-2010 \\
\hline Complete List of Authors: & $\begin{array}{l}\text { Nagaraja, Ravi; Royal Aberdeen Childrens Hospital, Anaesthesia } \\
\text { and Intensive care } \\
\text { Wilson, Morven; Royal Aberdeen Childrens Hospital, Anaesthesia } \\
\text { and Intensive care } \\
\text { Wilson, Graham; Royal Aberdeen Childrens Hospital, Anaesthesia } \\
\text { Marciniak, Bruno; Hopital Jeanne de Flandre, Pole d'Anesthesia } \\
\text { Reanimation } \\
\text { Engelhardt, Thomas; Royal Aberdeen Childrens Hospital, } \\
\text { Department of Anaesthesia and Intensive Care }\end{array}$ \\
\hline Key Words: & Ultrasound, Laryngeal Mask Airway, Internal Jugular vein \\
\hline \multicolumn{2}{|c}{} \\
\hline
\end{tabular}

\section{SCHOLARONE Manuscripts}


The anatomic relationship between the internal jugular vein and the carotid artery in children after laryngeal mask insertion. An ultrasonographic study.

Ravi Gopal Nagaraja MBBS ${ }^{1}$; Morven Wilson $\mathrm{MBChB}^{1}$; Graham Wilson $\mathrm{MBChB}^{1}$; Bruno Marciniak $\mathrm{MD}^{2}$; Thomas EngelhardtMD, $\mathrm{PhD}^{1}$

${ }^{1}$ Royal Aberdeen Children's Hospital, Foresterhill, Aberdeen, United Kingdom

${ }^{2}$ Pôle d'Anesthésie Réanimation. Hôpital Jeanne de Flandre. CHRU Lille, France

Author for correspondence:

Dr Ravi Gopal Nagaraja

Department of Anaesthesia,

Aberdeen Royal Infirmary,

Foresterhill Road, Aberdeen

AB25 2ZA

Email: ravinagaraja@ nhs.net 


\begin{abstract}
:
Background: Central venous cannulation although challenging in children and prone to complications is frequently required for total parentral nutrition and infusion of drugs.

Aim: The aim of this study was to determine the anatomic relationship between the internal jugular vein (IJV) and carotid artery (CA) before, and after, insertion of laryngeal mask airway (LMA) in children using ultrasound.
\end{abstract}

Methods: Patients aged 2-16 yrs were recruited into this prospective study and divided into 3 groups of 20 patients each: group 1: LMA size 2, group 2:LMA size $2 \%$ and group 3: LMA size 3. Prior to, and following, LMA insertion, the position, depth and time to location of the vessels was recorded. All measurements were made at the level of the cricoid cartilage in a neutral head position in the spontaneously breathing patient during expiration. The IJV position in relation to the CA was noticed as anterior $(A)$, anterolateral $(A L)$, lateral $(L)$ or medial $(M)$.

Results: The position of the IJV was found to be in the anterolateral (AL) or anterior $(A)$ position to the CA in the majority of cases. The anatomic relationship changed in $10 / 120(8.3 \%)$ following insertion of the LMA. The mean depth was $0.80( \pm 0.15) \mathrm{cm}$ for the right IJV before LMA insertion and $0.84( \pm 0.17) \mathrm{cm}$ after insertion. Similar measurements were made on the left side $(0.81( \pm 0.14)$ $\mathrm{cm}$ and $0.83( \pm 0.18) \mathrm{cm})$. The diameter as well as the depth of the IJV increased with the age and weight of the patient. 
1

2

3

4

5

6

7

8 9

Keywords: Laryngeal mask airway, Internal jugular vein, ultrasound. 


\section{Introduction}

Central venous cannulation although challenging in children and prone to complications $(1,2)$ is often required for total parentral nutrition and infusion of drugs. Ultrasound guided central venous cannulation results in higher success rate and lower complications compared to landmark technique (3-6). The position of the internal jugular vein (IJV) in relation to the carotid artery (CA) has been studied in adults (7-9). Few studies have been reported in children, with one study demonstrating a variable position of the IJV in relation to the CA following tracheal intubation (10). This study describes the anatomic relationship between the IJV and CA before and after laryngeal mask (LMA) insertion.

\section{Methods}

Following local ethics committee approval and parental consent, a total of 60 healthy patients aged 2-16 years were recruited into this prospective study. The children were divided into different groups depending on their weight, Group1 (LMA size 2), Group 2 (LMA size $2 \frac{1}{2}$ ) and Group 3 (LMA size 3). Exclusion criteria included emergency surgery, patients requiring rapid sequence induction, parental refusal, patients with previous IJV cannulation and patients with known or suspected anatomical abnormality.

Following inhalational or intravenous induction of anaesthesia, the child was placed supine with the head in a neutral position. Ultrasound measurements of the neck were performed by a single investigator using a Sonosite (Micromaxx ${ }^{R}$ ultrasound system, Transducer SLA 13$6 \mathrm{MHz}, 25 \mathrm{~mm}$ broadband linear array). The ultrasound probe was placed perpendicular to the skin and the images were obtained from the right and left side of the neck at the level of the cricoid cartilage in the spontaneously breathing patient during expiration. The positions 
of the right and left IJV in relation to the CA, the depth and diameter of the vein, as well as the time taken to locate the vessel were determined. Any distortion of the vein in relation to the CA, depth and diameter were noted.

The IJV position in relation to the CA was noted as anterior $(A)$, anterolateral $(A L)$, lateral $(L)$ or medial (M). All measurements were repeated following insertion of the LMA. Data are expressed as mean \pm SD.

\section{Results}

Sixty patients were recruited into this study. Mean ( \pm 1 SD) age and weight were $3.45( \pm 6)$ years, $8( \pm 2)$ years, $12.3( \pm 1.4)$ years and $16.32( \pm 3.8) \mathrm{kg}, 26.6( \pm 2.9) \mathrm{kg}, 50.5( \pm 7.9) \mathrm{kg}$ for groups 1, 2 and 3 respectively.

The mean depth overall was $0.80( \pm 0.15) \mathrm{cm}$ for the right IJV before and $0.84( \pm 0.17) \mathrm{cm}$ after LMA insertion and $0.81( \pm 0.14) \mathrm{cm}$ and $0.83( \pm 0.18) \mathrm{cm}$ on the left side. (Table 1$)$ The position of the IJV was found to be in the anterolateral $(\mathrm{AL})$ or anterior $(\mathrm{A})$ position in relation to the CA in the majority of cases and the anatomic relationship changed in 10/120 (8.3\%) following insertion of the LMA. (Figure 1) The diameter as well as the depth of the IJV increased with the age and weight of the patient.

Mean duration for localization of the vessels was $4.3( \pm 0.9) \mathrm{s}$ and $4.2( \pm 1.0) \mathrm{s}$ for the right and left IJV, respectively. The LMA was easily identified using ultrasound. 


\section{Discussion}

The use of ultrasound for central venous access is associated with a lower technical failure rate; reduction in complications and faster access. The success of IJV cannulation in infants and children has been reported in different studies to vary from $77 \%$ to $97.2 \%(1,11)$. The use of ultrasound results in an $86 \%$ relative risk reduction of failure and $57 \%$ reduction in complications compared to landmark techniques (4). Verghese et al have demonstrated a $100 \%$ success rate without arterial puncture versus $77 \%$ with $25 \%$ carotid puncture in children below 12 months using ultrasound (3). Internal jugular vein cannulation by landmark methods is often difficult and carries a high incidence of CA puncture due to the close proximity and the small calibre of the vessels (11). In addition, there are anatomic variations in the relative positions of IJV and CA $(7,8,10)$.

The LMA is useful airway device in children for a variety of surgical procedures. It is easy and atraumatic to insert, eliciting minimal autonomic response. Mason et al have demonstrated LMA is a safe device in children and in only $2.5 \%$ of cases had to use an alternate airway (12). A survey by Lopez-Gil et al in the use of LMA in children concluded that LMA provides a safe and effective form of airway management in experienced trainees (13). In children with difficult airway and intubation, LMA obtained a good airway in $73 \%$ of patients and an adequate airway in $27 \%$ of patients (14). LMA is a vital component of the difficult intubation trolley (15).

This current study determined the relationship between IJV and CA before and after laryngeal mask airway insertion at the level of cricoid cartilage in spontaneously breathing patients. Ultrasound location of the neck vessels was easy and did not delay the procedure. The IJV was anterolateral or anterior to the CA in the majority of patients with the head 
placed in the neutral position and the diameter as well as the depth of the IJV increased with the age and weight of the patient and is consistent with previous reports (10).

LMA insertion did alter the anatomical relationship between the CA and IJV in approximately $8 \%$ of the spontaneously breathing patients. This may be of relevance when attempting IJV cannulation using a landmark technique following initial ultrasound location of the IJV. This study, therefore, provides further evidence for the use of ultrasound for IJV cannulation following LMA insertion in spontaneously breathing children. 


\section{References}

1. Hayashi Y, Uchida O, Takaki O et al. Internal jugular vein catheterization in infants undergoing cardiovascular surgery; An analysis of the factors influencing successful catheterization. Anesth Analg 1992; 74: 688-93.

2. Kua JS,Tan IK. Airway obstruction following internal jugular vein cannulation. Anesthesia 1997; 52: 776-80.

3. Verghese ST, McGill WA, Patel RI et al. Ultrasound-guided internal jugular venous cannulation in infants. Anesthesiology 1999; 91: 71-7.

4. Hind D, Calvert N, McWilliams R et al. Ultrasonic locating devices for central venous cannulation: meta-analysis. BMJ 2003; 327: 361.

5. Slama M, Novara A, Safavian A et al. Improvement of internal jugular vein cannulation using an ultrasound-guided technique. Intensiv Care Med 1997; 23: 916-9.

6. Verghese ST, McGill WA, Patel RI et al. Comparison of three techniques for internal jugular vein cannulation in infants. Pediatr Anesth 2000; 10: 505-11.

7. Denys BG, Uretsky BF. Anatomical variation of the internal jugular vein location: impact on central venous access. Crit Care Med 1991; 19: 1516-9.

8.Troianos CA, Kuwik RJ, Pasqual JR et al. Internal jugular vein and carotid artery anatomic Relation as determined by ultrasonography. Anesthesiology 1996; 85: 43-8.

9. Riopelle JM, Ruiz DP, Hunt JP et al. Circumferential adjustment of ultrasound probe position to determine the optimal approach to the internal jugular vein: a non-invasive geometric study in adults. Anesth Analg 2005; 100: 512-9.

10.Roth B, Marciniak B, Engelhardt T et al. Anatomic relationship between the internal jugular vein and the carotid artery in pre-school children - an ultrasonographic study. Pediatr Anesth 2008; 18: 752-6.

11. Prince SR, Sullivan RL, Hackel A. Percutaneous catheterisation of the internal jugular vein in infants and children. 1976; 44: 170-4.

12. Mason DG, Bingham RM. The laryngeal mask airway in children. Anaesthesia 1990; 45: 760-3.

13.Lopez-Gil M, Brimacombe J, Alvarez M. Safety and efficacy of the laryngeal mask airway: A prospective survey of 1400 children. Anaesthesia 1996; 51: 969-72. 

4

7

8

9

10

11

12

13

14

15

16

17

18

19

20

21

22

23

24

25

26

27

28

29

30

31

32

33

34

35

36

37

38

39

40

41

42

43

44

45

46

47

48

49

50

51

52

53

54

55

56

57

58

59

60

14. Walker RWM. The laryngeal mask airway in the difficult paediatric airway: an assessment of positioning and use in fibreoptic intubation. Pediatr Anesth 2000; 10: 53-8.

15. Difficult airway society guidelines.

http://www.das.uk.com/guidelines/guidelineshome.html (accessed 18 August 2010). 


\section{Table 1}

Depths and diameters of the internal jugular vein before and after LMA insertion in spontaneously breathing patients. Results are mean $( \pm S D)$ in $\mathrm{mm}$.

\begin{tabular}{|c|c|c|c|c|}
\hline \multirow[t]{2}{*}{ SIZE 2} & \multicolumn{2}{|c|}{ DEPTH } & \multicolumn{2}{|l|}{ DIAMETER } \\
\hline & RIGHT & LEFT & RIGHT & LEFT \\
\hline BEFORE LMA & $0.70 \pm 0.19$ & $0.71 \pm 0.2$ & $1.18 \pm 0.26$ & $1.11 \pm 0.28$ \\
\hline AFTER LMA & $0.71 \pm 0.19$ & $0.71 \pm 0.18$ & $1.28 \pm 0.3$ & $1.15 \pm 0.29$ \\
\hline
\end{tabular}

\begin{tabular}{|c|c|c|c|c|c|}
\hline \multirow[t]{2}{*}{ SIZE 2.5} & \multirow[t]{2}{*}{$(n=20)$} & \multicolumn{2}{|c|}{ DEPTH } & \multicolumn{2}{|c|}{ DIAMETER } \\
\hline & & RIGHT & LEFT & RIGHT & LEFT \\
\hline & BEFORE LMA & $0.73 \pm 0.16$ & $0.76 \pm 0.14$ & $1.21 \pm 0.32$ & $1.19 \pm 0.32$ \\
\hline & AFTER LMA & $0.78 \pm 0.16$ & $0.75 \pm 0.13$ & $1.26 \pm 0.35$ & $1.18 \pm 0.32$ \\
\hline
\end{tabular}

\begin{tabular}{|c|c|c|c|c|}
\hline SIZE 3 & $\begin{array}{l}\text { DEPTH } \\
\text { RIGHT }\end{array}$ & LEFT & $\begin{array}{c}\text { DIAMETER } \\
\text { RIGHT }\end{array}$ & LEFT \\
\hline BEFORE LMA & $0.98 \pm 0.28$ & $0.97 \pm 0.22$ & $1.36 \pm 0.31$ & $1.01 \pm 0.33$ \\
\hline AFTER LMA & $1.03 \pm 0.29$ & $1.04 \pm 0.23$ & $1.34 \pm 0.33$ & $1.06 \pm 0.32$ \\
\hline
\end{tabular}


Figure 1

RIGHT

SIZE 2

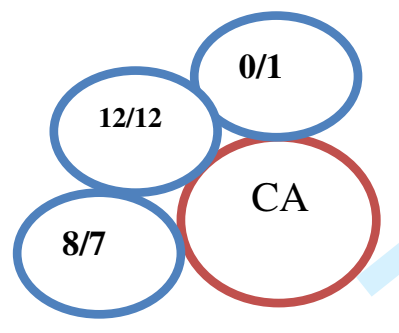

SIZE 2.5

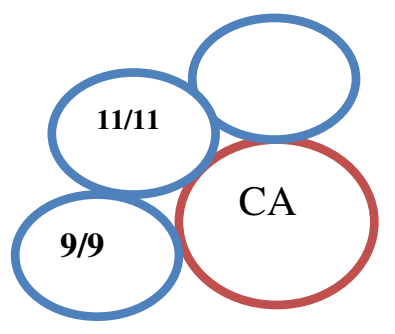

SIZE 3

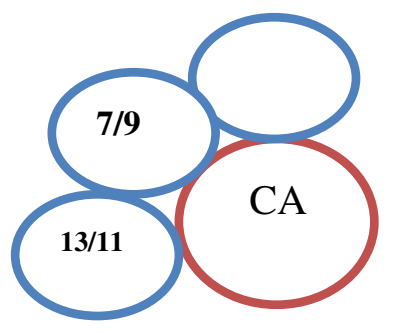

\section{LEFT}
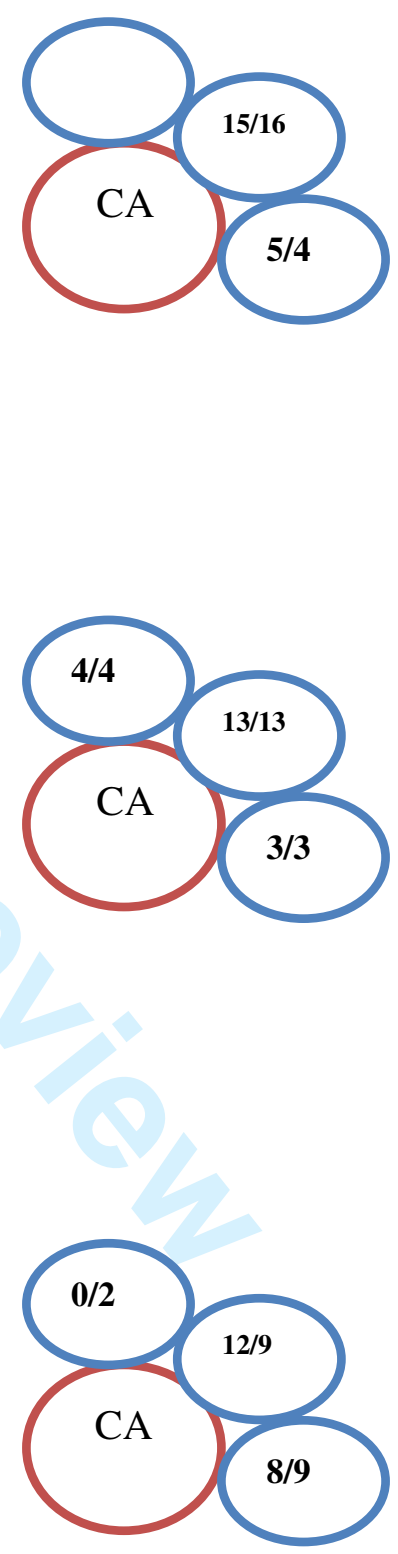

Relationship between internal jugular vein and carotid artery. The figures represent the total number of cases before/ after LMA insertion in each group. 